\title{
ANÁLISE DA QUALIDADE DOS CURSOS DO PROGRAMA UNIVERSIDADE PARA TODOS (PROUNI)
}

\author{
Camila Yuri Santana Ikuta (USP)* \\ http://orcid.org/0000-0003-0300-1124 \\ Gladys Beatriz Barreyro (USP)** \\ http://orcid.org/0000-0002-2714-5811
}

\section{RESUMO}

0 artigo apresenta resultados de pesquisa que investigou a qualidade dos cursos que ofertaram bolsas do Programa Universidade para Todos (ProUni), uma política implementada em 2005 com o objetivo de conceder bolsas de estudos de cursos de graduação em instituições de ensino superior privadas. Foi realizada análise quantitativa de dados dos cursos que ofertaram bolsas ProUni no município de São Paulo-SP em 2014, no que tange aos resultados de avaliação do Conceito Preliminar de Curso. Os resultados indicaram que os cursos selecionados que ofertaram o ProUni acompanharam a tendência de resultados de avaliação, não destoando dos resultados gerais dos cursos da educação superior brasileira. Entretanto, há uma parcela de cursos com ausência de conceito ou de reconhecimento, o que traz incertezas sobre a qualidade ofertada. Verificaram-se, também, diferenças em relação aos resultados conforme o grau acadêmico (bacharelados/tecnólogos), tipo de bolsa (integral/parcial) e área dos cursos.

Palavras-chave: Educação superior. Avaliação da educação superior. Política educacional.

\section{ABSTRACT}

\section{QUALITY ANALYSIS OF COURSES GIVEN BY THE UNIVERSITY FOR ALL PROGRAM (PROUNI)}

The article presents the outcome of a research on the quality of courses which offered scholarships through the University for All Program (ProUni), a policy implemented in 2005, whose purpose is to grant scholarships to undergraduates in private higher education institutions. Quantitative analysis was conducted for the courses with ProUni scholarships in São Paulo-SP in 2014, using assessment data from the Course Preliminary Rating. Results showed that selected courses

\footnotetext{
Mestre em Educação pela Universidade de São Paulo (USP). São Paulo, São Paulo Brasil. Técnica do Departamento Intersindical de Estatística e Estudos Socioeconômicos (DIEESE). E-mail: camilaikuta@usp.br

** Doutora em Educação pela Universidade de São Paulo (USP). São Paulo, São Paulo Brasil. Professora no Programa de PósGraduação em Educação e na Escola de Artes, Ciências e Humanidades da Universidade de São Paulo (EACH/USP). E-mail: gladysb@usp.br
} 
providing ProUni scholarships followed the tendency in the assessment results, as they were similar to overall results of higher-education courses in Brazil. However, some courses have no rating or are not legally acknowledged, shedding uncertainty on the quality provided. Differences were also found in the results according to the academic degree (bachelor's or technology), type of scholarship (full/partial) and area of knowledge.

Keywords: Higher education. Assessment of higher education. Educational policy.

\section{RESUMEN}

\section{ANÁLISIS DE LA CALIDAD DE LAS CARRERAS DEL PROGRAMA UNIVERSIDAD PARA TODOS (PROUNI)}

El texto analiza la calidad de las carreras que ofrecieron becas del Programa Universidad para Todos (ProUni), una política implementada desde 2005 que tiene por objetivo conceder becas de estudios de grado, en instituciones de educación superior privadas. Se analizaron cuantitativamente los resultados de la evaluación Concepto Preliminar de Curso en las carreras que ofrecieron becas del ProUni en la ciudad de São Paulo, Brasil, en 2014. Los resultados indicaron que las carreras seleccionadas del ProUni acompañaron la tendencia de los resultados de la evaluación, sin diferenciarse de los resultados generales de todas las carreras del país. Sin embargo, existe un grupo de carreras con ausencia de concepto y sin reconocimiento (procedimiento regulatorio oficial), lo que genera dudas acerca de su calidad. Se verificaron también diferencias en relación a los resultados, de acuerdo con el grado académico (bachillerato/ tecnológico), tipo de beca (integral/parcial) y área de conocimiento.

Palabras clave: Educación superior. Evaluación de la educación. Política educativa.

\section{Introdução}

O texto apresenta resultados de pesquisa de mestrado ${ }^{1}$ (IKUTA, 2016a) que investigou a questão da qualidade dos cursos que ofertaram bolsas no Programa Universidade para Todos (ProUni), política educacional implementada pela Lei $n$ o $11.096 / 2005$ (BRASIL, 2005). 0 ProUni é voltado ao segmento de educação superior e possui como premissa a concessão de bolsas de estudos para estudantes de cursos de graduação e sequenciais de formação específica em Instituições de Ensino Superior

1 Sobre os procedimentos éticos, a pesquisa utilizou informações de interesse público (dados quantitativos), nos termos do Art. 10 da Lei no 12.527/2011 (BRASIL, 2011) (Lei de Acesso à Informação).
(IES) privadas. Para discutir a questão da qualidade, foi realizada uma pesquisa de cunho quantitativo e de análise descritiva, a partir do cruzamento de dados sobre os resultados de avaliação dos cursos que ofertaram bolsas do ProUni no primeiro semestre de 2014, no município de São Paulo-SP. A referência de avaliação da qualidade escolhida foi a do Conceito Preliminar de Curso (CPC) - que é considerado, oficialmente, o indicador de qualidade da Educação Superior voltado aos cursos superiores brasileiros, no âmbito do Sistema Nacional de Avaliação da Educação Superior (SINAES).

Este texto foi organizado em quatro partes: a primeira trata do Programa Universidade para 
Todos (ProUni): implementação da política, público-alvo e debate acadêmico; a segunda apresenta o SINAES e o funcionamento da avaliação da qualidade de cursos de graduação no país; na terceira parte, estão explicitados o percurso metodológico e procedimentos de pesquisa utilizados; e na quarta, são apresentados e discutidos os resultados obtidos. Em seguida, as considerações finais.

\section{Programa Universidade para Todos (ProUni)}

O Programa Universidade para Todos (ProUni) é uma política educacional do Governo Federal implementada pela Lei no $11.096 / 2005$ (BRASIL, 2005). Objetiva a concessão de bolsas de estudos integrais (100\%) e parciais (50\% ou $25 \%$ ) a estudantes de cursos de graduação e sequenciais de formação específica, em Instituições de Ensino Superior (IES) privadas (com ou sem fins lucrativos). Desde a implementação do Programa, em 2005, até o primeiro semestre de 2017, foram ofertadas mais de 3 milhões $^{2}$ de bolsas de estudo em todo o país (BRASIL, 2017).

O público-alvo do Programa são estudantes egressos do ensino médio da rede pública de ensino, além de estudantes da rede particular, desde que tenham cursado na condição de bolsistas integrais. Concomitantemente, há critério de seleção baseado na renda: o candidato precisa ter uma renda bruta mensal per capita de seu grupo familiar de até um salário mínimo e meio para requerer bolsas integrais; e de até três salários mínimos para requerer bolsas parciais. 0 Programa também possui reserva de bolsas por raça/cor (indígenas, pardos e pretos), para pessoas com deficiência e para a adesão de professores da rede pública de ensino (estes últimos, para bolsas em cursos de licenciatura).

As IES que aderem ao Programa recebem, em contrapartida, a isenção de impostos

2 Não necessariamente preenchidas. e contribuições, todos incidentes sobre a prestação de serviços destas instituições: Imposto de Renda das Pessoas Jurídicas (IRPJ), Contribuição Social sobre o Lucro Líquido (CSLL), Contribuição Social para o Financiamento da Seguridade Social (COFINS) e Contribuição para o Programa de Integração Social (PIS).

No que tange ao contexto educacional, o Programa Universidade para Todos surge em um cenário marcado por forte expansão das IES privadas, beneficiadas pela legislação da educação superior brasileira, que facilitou a abertura e a manutenção de entidades de caráter privado - especialmente as de fins lucrativos (ALMEIDA, 2012). Essas entidades chegaram, após um período de expansão significativa, ${ }^{3}$ em um quadro de ociosidade de vagas (CARVALHO, 2006; SOUSA, 2010). Por outro lado, também era um momento em que a ampliação do acesso à educação superior era uma questão latente, pois apenas 10,7\% das pessoas de 18 a 24 anos frequentavam esse nível em 2004, segundo dados do Censo da Educação Superior, divulgado pelo Instituto Nacional de Pesquisas Educacionais Anísio Teixeira (INSTITUTO NACIONAL DE PESQUISAS EDUCACIONAIS ANÍSIO TEIXEIRA, 2005). Além disso, constituía-se como uma grande necessidade atender a uma das metas do Plano Nacional de Educação (PNE) 20012010, que pretendia alcançar a taxa bruta de $50 \%$ de matrículas no ensino superior, e a taxa líquida de 33\%. Ainda, o ProUni surgiu, também, com a justificativa da necessidade de aumentar o acesso das camadas menos favorecidas ao ensino de nível superior, por meio de um discurso de maior justiça social (CARVALHO, 2006).

Os debates após a instituição do Programa giraram em torno de temas como a democratização do acesso, a inclusão e a mobilidade social que a política traz como premissas, já

3 Em 2005, 89,3\% das IES brasileiras eram privadas (INSTITUTO NACIONAL DE PESQUISAS EDUCACIONAIS ANÍSIO TEIXEIRA, 2005). 
que o Programa é também observado enquanto política de ação afirmativa (em que pesem suas contradições). É fato que políticas como o ProUni, ao favorecer o acesso da população com baixo poder aquisitivo a um espaço tradicionalmente marcado por grande concentração de renda, o universitário (RISTOFF, 2014), podem ajudar a reduzir, ainda que de forma lenta, essa situação de desigualdade (BARREYRO; COSTA, 2015).

Por outro lado, o Programa traz a polêmica questão da isenção fiscal que é concedida às IES participantes, e o consequente fortalecimento do setor privado em detrimento do setor público. Além disso, a política sofreu críticas à vulnerável permanência do aluno bolsista nas instituições, e em relação à questão da heterogeneidade e/ou qualidade questionável das instituições participantes, bem como dos cursos que são oferecidos (ALMEIDA, 2012; CATANI; HEY; GILIOLI, 2006; PAULA, 2006).

Após mais de dez anos de sua implementação, os impactos da política ainda estão sendo investigados. No que tange aos cursos em que são ofertadas bolsas do Programa, apesar de existir um relativo controle em relação à avaliação de infraestrutura, corpo docente, formato do curso etc. - por meio de critérios de desempenho aferidos no âmbito do Sistema Nacional de Avaliação da Educação Superior (SINAES) -, ainda existem muitos entraves para se mensurar a qualidade desses cursos, que são selecionados apenas na esfera privada. A partir da identificação desta problemática, que também pode ser considerada uma lacuna de pesquisa, o estudo aqui apresentado teve como objetivo realizar uma investigação sobre a qualidade dos cursos com oferta de bolsas do ProUni.

A seguir, serão apresentados alguns dados quantitativos sobre os cursos do ProUni, buscando realizar uma caracterização das condições de oferta dessa política educacional. A mesma fonte de dados será utilizada posteriormente para a análise da qualidade.

\section{Dados sobre a oferta do ProUni} no município de São Paulo-SP

Para este estudo, foram analisados os dados de oferta do ProUni no município de São Paulo-SP, no primeiro semestre de $2014 .{ }^{4}$ As informações foram obtidas via Lei de Acesso à Informação, ${ }^{5}$ possibilitando maior detalhamento das condições de oferta de bolsas.

Considerando esse recorte, foram ofertadas 26.841 bolsas, representando $41,7 \%$ da oferta do estado de São Paulo no mesmo período (a região Sudeste é a que mais concentra, historicamente, a oferta de bolsas ProUni). Desse total de mais de 26 mil bolsas, os 20 primeiros cursos com maior oferta estão visivelmente concentrados na área de Ciências Humanas (Administração, Direito e Pedagogia), conforme é possível observar no Gráfico 1. Eram, exatamente, os três cursos com maior número de matrículas, segundo o Censo da Educação Superior $2013^{6}$ - o que é esperado, considerando que a oferta de bolsas pelo ProUni está diretamente atrelada ${ }^{7}$ ao número de estudantes efetivamente matriculados em cada IES.

40 processo seletivo do ProUni é realizado de forma semestral, sendo que os primeiros semestres de cada ano costumam registrar maior oferta de bolsas (BRASIL, 2017).

5 Um importante aspecto identificado na revisão bibliográfica foi a falta de estatísticas desagregadas e séries históricas sobre o Programa e que fossem disponibilizadas de forma pública, o que permitiria uma análise mais abrangente sobre seus impactos. 0 recorte temporal e geográfico dos dados da pesquisa deve-se tanto ao grande número de informações trabalhadas, quanto à data da solicitação no sistema, que ocorreu entre os meses de março e abril de 2014.

6 Segundo os dados do Censo 2013 (INSTITUTO NACIONAL DE PESQUISAS EDUCACIONAIS ANÍSIO TEIXEIRA, 2015), Administração: 800.114 matrículas, com participação de $11 \%$ no total; Direito: 769.889 matrículas ou 10,5\% do total; Pedagogia: 614.835 matrículas ou 8,4\% do total.

7 A IES participante e que seja com fins lucrativos ou sem fins lucrativos não beneficente precisa oferecer, no mínimo, uma bolsa integral para cada 10,7 estudantes pagantes e matriculados; ou, alternativamente, oferecer uma bolsa integral para cada 22 estudantes pagantes e matriculados, desde que ofereça adicionalmente bolsas parciais, condicionadas ao valor dos benefícios concedidos no equivalente de $8,5 \%$ da receita anual dos períodos letivos (BRASIL, 2005). 
Gráfico 1 - Principais cursos com maior oferta de bolsas ProUni no processo seletivo 1/2014 (em \%). Município de São Paulo, SP

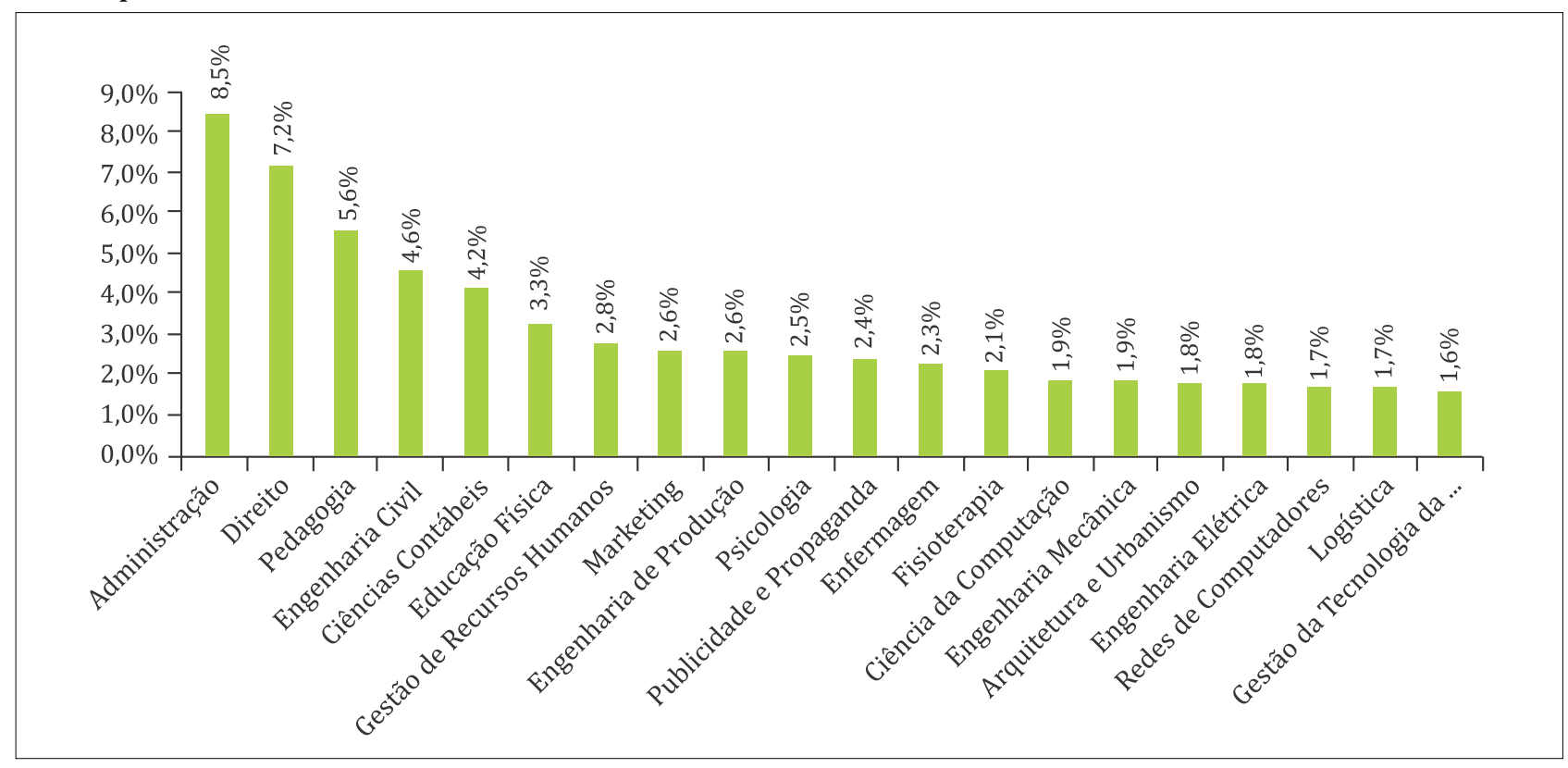

Fonte: Ikuta (2016a, p. 131).

Nota: A soma dos 20 cursos não reflete o total ofertado no semestre.

Boa parte dos cursos apresentados entre os 20 primeiros a oferecer mais vagas figuram na lista de cursos de graduação mais concorridos do país, tais como: Engenharia Civil (e outras Engenharias), Direito, Psicologia, Publicidade e Propaganda e Arquitetura e Urbanismo. Os cursos de graduação de Bacharelado são maioria (15 de 20); já os cursos de Licenciaturas, como Geografia, Matemática, História, Filosofia e outras, não aparecem nessa listagem.

Vale ressaltar, também, outros cursos que não aparecem na lista, mas que são prestigiados socialmente, com um alto custo das mensalidades e marcados pela acirrada concorrência nos principais vestibulares do país, como Medicina, por exemplo, que apresenta uma quantidade reduzida de bolsas (figurou na $72^{\underline{a}}$ posição no primeiro semestre de 2014 , com apenas 53 bolsas).

Na Tabela 1 são listadas as 20 IES que mais ofertaram bolsas no processo seletivo do primeiro semestre de 2014, no município de São Paulo-SP. A concentração em grandes grupos universitários é notória: Universidade São Judas Tadeu (USJT), com 7.683 bolsas, ou 28,6\%; Universidade Nove de Julho (UNINOVE), com $10,8 \%$, ou 2.886 bolsas; e Universidade Paulista (UNIP), com 10,1\%, ou 2.720 bolsas. Somente estas três instituições juntas somam quase $50 \%$ do total ofertado no semestre, indicando a pouca pulverização de instituições e, por consequência, podendo indicar a pouca diversificação do modelo de ensino ofertado pelo ProUni. Essas 20 IES representaram 91\% do total de bolsas oferecidas no semestre.

Tabela 1 - Principais Instituições de Ensino Superior que mais ofertaram bolsas ProUni no processo seletivo 1/2014Município de São Paulo-SP

\begin{tabular}{|l|c|c|}
\hline \multicolumn{1}{|c|}{ Instituição de Ensino Superior } & $\begin{array}{c}\text { Número } \\
\text { de bolsas } \\
\text { ofertadas }\end{array}$ & $\begin{array}{c}\% \text { do total } \\
\text { ofertado no } \\
\text { semestre* }\end{array}$ \\
\hline Universidade São Judas Tadeu (USJT) & 7.683 & $28,6 \%$ \\
\hline Universidade Nove de Julho (UNINOVE) & 2.886 & $10,8 \%$ \\
\hline
\end{tabular}




\begin{tabular}{|l|c|c|}
\hline \multicolumn{1}{|c|}{ Instituição de Ensino Superior } & $\begin{array}{c}\text { Número } \\
\text { de bolsas } \\
\text { ofertadas }\end{array}$ & $\begin{array}{c}\text { \% do total } \\
\text { ofertado no } \\
\text { semestre* }\end{array}$ \\
\hline Universidade Palista (UNIP) & 2.720 & $10,1 \%$ \\
\hline Universidade Ibirapuera (UNIB) & 1.830 & $6,8 \%$ \\
\hline Universidade Anhembi Morumbi (UAM) & 1.302 & $4,9 \%$ \\
\hline Faculdade São Paulo (FACSP) & 1.000 & $3,7 \%$ \\
\hline Centro Universitário das Faculdades Metropolitanas Unidas (FMU) & 980 & $3,7 \%$ \\
\hline Centro Universitário Anhanguera de São Paulo & 756 & $2,8 \%$ \\
\hline Universidade Cruzeiro do Sul (UNICSUL) & 749 & $2,8 \%$ \\
\hline Faculdade Sumaré (ISES) & 676 & $2,5 \%$ \\
\hline Faculdade de São Paulo (FATEMA) & 589 & $2,2 \%$ \\
\hline Faculdade Paulus de Tecnologia e Comunicação (FAPCOM) & 587 & $2,2 \%$ \\
\hline Universidade Cidade de São Paulo & 573 & $2,1 \%$ \\
\hline Pontifícia Universidade Católica de São Paulo (PUC-SP) & 396 & $1,5 \%$ \\
\hline Universidade de Santo Amaro (UNISA) & 381 & $1,4 \%$ \\
\hline Faculdade Centro Paulistano & 314 & $1,2 \%$ \\
\hline Centro Universitário Senac (SENACSP) & 305 & $1,1 \%$ \\
\hline Centro Universitário Estácio Radial de São Paulo - Estácio Uniradial & 241 & $0,9 \%$ \\
\hline Faculdade Flamingo & 227 & $0,8 \%$ \\
\hline Faculdade Paschoal Dantas (FPD) & 223 & $0,8 \%$ \\
\hline Fonte & & \\
\hline
\end{tabular}

Fonte: Ikuta (2016a, p. 134).

Nota: A soma das 20 instituições não reflete o total ofertado no semestre.

Foi observada a ausência de instituições de ensino tidas como "de elite", ou seja, possuidoras de grande prestígio social, caracterizadas como "especializadas em um determinado nicho acadêmico, direcionadas ao extrato de maior renda" (CARVALHO, 2013, p. 768), como, por exemplo: a Escola Superior de Propaganda e Marketing (ESPM), a Fundação Getúlio Vargas (FGV) e o Instituto de Ensino e Pesquisa (INSPER), também localizadas no mesmo município, e que não registraram o oferecimento de bolsas ProUni no semestre de referência.

Os dados apresentados sobre a oferta do ProUni nesse período e localidade indicam, portanto, a alta concentração do oferecimento de bolsas em poucas IES participantes, muitas vezes pertencentes a grandes grupos educacionais; e em relação aos cursos ofertados, as bolsas estavam concentradas na área de Ciências Humanas (Administração, Direito e Pedagogia), ou seja, uma área caracterizada por cursos de baixo custo operacional. No entanto, esse quadro reflete um patamar muito semelhante ao identificado no sistema de educação superior brasileiro em geral.

Na seção seguinte será apresentado o funcionamento geral do Sistema Nacional de Avaliação da Educação Superior (SINAES) e os procedimentos de avaliação da qualidade de cursos de graduação no país, com destaque para o Conceito Preliminar de Curso (CPC), cujos resultados, na forma de indicadores, 
serão utilizados como referência de qualidade neste estudo.

\section{A avaliação da qualidade dos cursos no SINAES}

O movimento expansionista e de diversificação da educação superior verificado, em especial, a partir dos anos 1990, gerou a necessidade de fiscalização de instituições e cursos por parte do Estado, de forma a avaliar e certificar se há comprometimento com a prestação de serviços educacionais de qualidade - e qual seria essa noção de qualidade. Nessa perspectiva, a partir das décadas de 1980 e 1990, a qualidade começou a entrar em discussão na agenda de políticas da educação superior: "com a expansão do Estado avaliador, a qualidade, como seu substrato, adquire força" (MOROSINI, 2009, p. 167).

Sendo uma responsabilidade do Estado brasileiro assegurar educação de qualidade a todos e em todos os níveis, ${ }^{8}$ os documentos oficiais de políticas educacionais procuraram deixar clara uma relação direta entre instrumentos de avaliação e qualidade da educação superior. Sabe-se, no entanto, que a avaliação pode ser compreendida numa imensa gama de aspectos, que envolvem não apenas as dimensões do ensino, mas também de gestão, gerenciamento, recursos, estrutura, condições sociais e econômicas, diversidade de modelos de instituição superior, entre outros.

O Sistema Nacional de Avaliação da Educação Superior (SINAES), criado pela Lei ${ }^{\circ}$ 10.861, de 2004 (BRASIL, 2004), constitui a atual política de avaliação da educação superior no país. Seu objetivo é o de realizar um processo de avaliação da educação superior orientado em três eixos: instituições de educação superior, cursos de graduação e desempenho acadêmico dos estudantes.

8 Constituição Federal de 1988: Capítulo III - "Da Educação, da Cultura e do Desporto", Art. 206: "O ensino será ministrado com base nos seguintes princípios: [...] VII - garantia de padrão de qualidade" (BRASIL, 1999).
Assim, a avaliação institucional foca nas instituições de ensino superior (IES), por meio de autoavaliação realizada pelas Comissões Permanentes de Avaliação, criadas para tal fim nas IES, e de avaliação externa in loco; a avaliação de cursos consiste na visita de avaliadores aos cursos para verificar aspectos das dimensões de infraestrutura, corpo docente e organização didático-pedagógica; e o desempenho acadêmico dos estudantes é aferido pela aplicação do Exame Nacional de Desempenho dos Estudantes (ENADE), que é constituído de uma prova e de questionário dirigido aos estudantes (BRASIL, 2004).

Em 2008, foram criados os indicadores Conceito Preliminar de Curso (CPC) e Índice Geral de Cursos (IGC), com o intuito de avaliar cursos e instituições, respectivamente.

O Conceito Preliminar de Curso (CPC) é considerado, atualmente, o indicador de qualidade da Educação Superior voltado aos cursos superiores de graduação, no âmbito do SINAES (INSTITUTO NACIONAL DE PESQUISAS EDUCACIONAIS ANÍSIO TEIXEIRA, 2014a). É calculado no ano seguinte à realização do ENADE e divulgado anualmente, possuindo como pilares de avaliação as seguintes dimensões: corpo docente, instalações físicas e organização didático-pedagógica - composta de informações, já existentes, sobre as IES que ofertam os cursos e também respostas dos estudantes ao questionário sobre as três dimensões consideradas -, além do desempenho médio dos estudantes na prova do ENADE (INSTITUTO NACIONAL DE PESQUISAS EDUCACIONAIS ANÍSIO TEIXEIRA, 2013). Cada uma das dimensões citadas possui pesos específicos na fórmula de cálculo do indicador, ou seja: o CPC é considerado como uma média ponderada ${ }^{9}$ de diversas medidas, previamente estabelecidas, relacionadas à qualidade de um curso.

9 Outros detalhes metodológicos, mais específicos em relação ao cálculo do indicador, estão na seção "Metodologia e Procedimentos de Pesquisa". 
Um dos procedimentos previstos no SINAES, para a avaliação de cursos, são as visitas presenciais realizadas por comissões de especialistas. Por possuir um caráter preliminar, como o próprio nome sugere, a intenção oficial é que o CPC possa subsidiar esses processos de avaliação in loco nas instituições de ensino (INSTITUTO NACIONAL DE PESQUISAS EDUCACIONAIS ANÍSIO TEIXEIRA, 2013).

Assim como as demais avaliações relativas ao SINAES, a nota final do CPC deve ser em uma escala em cinco níveis ( 1 a 5), considerando-se satisfatório o igual ou superior a três (BRASIL, 2010). No caso de obtenção de CPC satisfatório, a visita presencial torna-se facultativa; os cursos que obtiverem CPC insatisfatório e não seguirem o trâmite da avaliação presencial são considerados em situação irregular.

$\mathrm{Na}$ revisão da literatura sobre o $\mathrm{CPC}$, foi possível perceber que as concepções que norteiam sua relação com o SINAES e os próprios cálculos e mudanças metodológicas do indicador, desde sua criação, são muito discutidos e questionados. Nesse sentido, torna-se importante entender as potencialidades e fragilidades desses indicadores de avaliação, pois não são resultados de escolhas neutras (BARREYRO, 2008).

Alguns autores alertam para a falta de associação do CPC com os critérios norteadores do SINAES; e que a instituição do CPC foi uma prática que sinalizou, por parte do Ministério da Educação (MEC), apenas um movimento operacional, e não um modelo amplamente discutido no cenário de avaliação do país (BARREYRO; ROTHEN, 2014).

Apesar disso, sabe-se que o CPC passou (e está passando) por diversas reformulações metodológicas desde sua criação - inclusive em 2008, 2011 e 2013 (IKUTA, 2016b), o que evidencia que esse indicador passa por constante transformação e aprimoramento, assim como diversos aspectos do próprio SINAES. Contudo, é notório que o CPC possui um peso significativo enquanto indicador oficial de qualidade no sistema de avaliação da educação superior - especialmente diante da grande expansão do segmento privado nas últimas décadas, o que gerou a necessidade de adoção de políticas de controle da qualidade dessa oferta.

\section{Metodologia e procedimentos de pesquisa}

Dentre as diversas formas de investigação da política do Programa Universidade para Todos, foi definida como problemática de pesquisa a questão da qualidade dos cursos, em especial por duas justificativas: 1) o levantamento bibliográfico sobre o tema indicou diversos questionamentos de pesquisadores(as) acerca da qualidade educacional das instituições participantes do ProUni, bem como dos cursos que são oferecidos, sendo esta uma lacuna identificada para investigação; 2) abertura de possibilidades de pesquisa pela exploração dos dados quantitativos ${ }^{10}$ sobre a oferta do Programa, obtidos pela Lei de Acesso à Informação/MEC.

Assim, a pesquisa apresentada neste artigo possuiu o objetivo geral de discutir a questão da qualidade dos cursos que ofertaram bolsas do ProUni, por meio de investigação de cunho quantitativo.

Para desenvolver a estratégia de análise dos dados, primeiramente foi necessário entender qual é o procedimento atualmente existente, na legislação, para o controle da avaliação da qualidade dos cursos do ProUni. A partir de pesquisa documental sobre a política, foi constatado que a legislação referente ao Programa não explicita diretamente qual instrumento é utilizado como parâmetro de qualidade para avaliação dos cursos superiores oferecidos, embora utilize critérios de desempenho do SINAES. Na Lei do ProUni, consta que "O MEC

10 A maior parte das pesquisas acadêmicas sobre o ProUni utiliza métodos qualitativos de pesquisa, como entrevistas com os bolsistas. A disponibilidade de dados quantitativos sobre o Programa, pelo advento da Lei de Acesso à Informação, em 2012, possibilitou, também, outras abordagens de pesquisa. 
desvinculará do ProUni o curso considerado insuficiente, sem prejuízo do estudante já matriculado, segundo critérios de desempenho do SINAES, por duas avaliações consecutivas [...]" (BRASIL, 2005). No entanto, no texto legal não há menção específica sobre qual indicador é utilizado para essa avaliação, ainda que o Conceito Preliminar de Curso (CPC) seja o indicador oficial de qualidade dos cursos na educação superior.

Considerando que não havia um critério de qualidade estabelecido diretamente na legislação, o próximo passo da pesquisa passou, então, pela definição própria de critérios para coleta, preparação e análise.

A escolha metodológica foi de realizar uma análise quantitativa, considerando a obtenção do banco de dados contendo informações bastante desagregadas e abrangentes sobre a oferta do Programa - as quais foram apresentadas, de forma resumida, na seção "Dados sobre a oferta do ProUni". São informações que identificam quais são os cursos e as instituições de ensino com oferta de bolsas, turnos, modalidades de ensino, municípios, processos seletivos e outros aspectos, o que viabilizou a análise proposta nesta pesquisa.

E, enquanto critério de qualidade, a escolha foi pela utilização dos resultados de avaliação no Conceito Preliminar de Curso (CPC), considerando que este é o indicador de qualidade oficialmente estabelecido no âmbito do SINAES/MEC, e que possui maior abrangência de informações disponíveis e sistematizadas, para a maioria dos cursos superiores brasileiros. Os resultados do CPC são divulgados na forma de notas (de cada componente e notas finais, em uma escala de 1 a 5), disponíveis por curso, instituição de ensino, município e outras variáveis, que são publicados anualmente e disponíveis para download no website do INEP.

Assim, o procedimento escolhido foi o cruzamento destas duas fontes de dados secundárias e distintas: dos cursos que ofertaram bolsas pelo ProUni e de seus respectivos resultados (notas finais) no indicador do CPC.

Em razão do recorte temporal dos dados obtidos sobre a oferta do ProUni, que são referentes ao processo seletivo do primeiro semestre de 2014, no município de São Paulo-SP, foram utilizados os respectivos resultados do CPC do ano de 2012 (INSTITUTO NACIONAL DE PESQUISAS EDUCACIONAIS ANÍSIO TEIXEIRA, 2014 b), que era o que estava disponível no momento daquele processo seletivo (ocorre defasagem na divulgação). 0 banco de dados do CPC 2012 continha resultados de avaliação da qualidade para 7.077 cursos, em 1.762 instituições de ensino superior do país (INSTITUTO NACIONAL DE PESQUISAS EDUCACIONAIS ANÍSIO TEIXEIRA, 2014b).

No cruzamento das informações, foi possível relacionar 243 cursos com oferta do ProUni aos resultados das notas finais do CPC. Existiam mais cursos com oferta ProUni no banco de dados obtido (total de 911); no entanto, nem todos puderam ser relacionados ao CPC, pois o indicador é atrelado diretamente à realização do ENADE, que avalia somente alguns cursos superiores por ano - seguindo um calendário em que determinados grupos e áreas são avaliados trienalmente. ${ }^{11}$

Para o tratamento e processamento dos bancos de dados, foi utilizado o software Microsoft Excel, e para a análise, procedimentos de estatística descritiva, ${ }^{12}$ ou seja, descrição e sumarização dos dados, mediante a construção de tabelas de frequência absoluta e relativa. A análise foi realizada considerando algumas desagregações como tipo de curso, tipo de bolsa ofertada e região geográfica.

110 CPC é divulgado com base nas áreas de enquadramento que foram avaliadas pelo Enade, de periodicidade trienal. Em 2012, estas áreas foram: Administração, Ciências Contábeis, Ciências Econômicas, Design, Direito, Jornalismo, Psicologia, Publicidade e Propaganda, Relações Internacionais, Secretariado Executivo, Tecnologias em: Gestão Comercial, Gestão de Recursos Humanos, Gestão Financeira, Logística, Marketing, Processos Gerenciais e Turismo. Por esta razão, foram selecionados somente cursos dentro dessas áreas.

12 Não foram utilizados métodos de inferência estatística, e por esta razão não se pretendeu a generalização dos resultados obtidos nesta pesquisa. 
Vale ressaltar alguns aspectos metodológicos mais específicos do cálculo do indicador CPC, que são de suma importância para a leitura e interpretação dos resultados. 0 primeiro aspecto é que seu cálculo é realizado por Unidade de Observação, e não necessariamente por "curso", ou seja: cada Unidade consiste no conjunto de cursos que compõe uma área de avaliação específica do Enade de uma IES em um determinado município (INSTITUTO NACIONAL DE PESQUISAS EDUCACIONAIS ANÍSIO TEIXEIRA, 2013), e não somente um curso em específico. Assim, quando se lê 243 "cursos", na verdade se tratam de 243 Unidades de Observação.

Além disso, cada resultado é calculado por “área de enquadramento" (como, por exemplo, Administração, Direito e outras) e, em razão da especificidade de cada área, há certas limitações na possibilidade de comparação de seus resultados entre áreas diferentes.

As notas de cada componente do CPC seguem uma fórmula estatística que é chamada de "afastamento padronizado", relacionando a nota dos componentes com a média nacional obtida pela área de avaliação (IKUTA, 2016b), para que seja possível calcular a nota contínua do CPC por meio dos pesos dos componentes, que então resultam na nota final (as faixas de 1 a 5).

Em decorrência disso, a concentração dos cursos avaliados em torno da faixa 3 (definida como média pelo INEP) será um fato recorrente durante o trabalho, pois esta é uma característica intrínseca aos resultados de distribuição padronizada, fator que gera maior homogeneização das notas (NUNES; FERNANDES; ALBRECHT, 2014); e que também acontece com outros indicadores do SINAES (BITTENCOURT et al., 2008). Portanto, a interpretação dos resultados, por meio de análise descritiva, procurou focar nas situações que se distanciam da média, ainda que de forma relativa (Conceitos 1 e 2 ou 4 e 5 ).

Além da nota final (que vai de 1 a 5), o banco de dados do CPC também contém o status de avaliação dos cursos, ou seja, se o curso estava sem avaliação naquele momento (Sem Conceito, ou Unidade com cursos não reconhecidos até o momento de divulgação do indicador), além de atos vencidos, sob supervisão etc. Essas situações, ainda que não sejam as notas do indicador, foram consideradas e utilizadas na análise pela compreensão de que são indicativos bastante preocupantes: eram cursos que estavam sem avaliação, ou em processo de, e que estavam participando de política governamental por meio da oferta de bolsas.

Por fim, vale ressaltar que a referência de aferição da qualidade escolhida para este estudo, na forma do Conceito Preliminar de Curso (CPC), não impediu sua posterior problematização, acerca dos limites e possibilidades teóricos e práticos do uso deste tipo de indicador.

A seguir são apresentados os resultados do cruzamento entre os dados dos cursos ProUni e os resultados de avaliação no CPC, os quais foram interpretados à luz da discussão sobre qualidade e avaliação da educação superior brasileira.

\section{Resultados: apresentação e discussão}

Nesta seção serão analisados os 243 cursos ProUni selecionados, em relação às respectivas notas finais do $\mathrm{CPC}$, desagregando-os por tipo de bolsa ofertada, por grau acadêmico, região geográfica e por áreas de enquadramento.

Na Tabela 2 estão apresentados os resultados obtidos na nota final do CPC dos 243 cursos que ofereceram bolsas do ProUni no primeiro semestre de 2014, no local de oferta do município de São Paulo-SP. Estes cursos representaram 26,7\% (243 de 911) do total de cursos que ofertaram bolsas do ProUni no semestre referido. 
Tabela 2 - Distribuição dos cursos que ofereceram bolsas no processo seletivo do ProUni 1/2014, no município de São Paulo, SP, segundo resultados do Conceito Preliminar de Curso (CPC) 2012

\begin{tabular}{|l|c|c|}
\hline \multirow{2}{*}{ CPC $\mathbf{2 0 1 2}$ - Resultado/situação } & \multicolumn{2}{|c|}{ Cursos com bolsas do ProUni - São Paulo-SP } \\
\cline { 2 - 3 } & $\mathbf{n}^{\circ}$ & $\mathbf{\%}$ \\
\hline CPC 2 & 29 & 11,9 \\
\hline CPC 3 & 130 & 53,5 \\
\hline CPC 4 & 36 & 14,8 \\
\hline CPC 5 & 3 & 1,2 \\
\hline Sem Conceito (SC) & 15 & 6,2 \\
\hline Unidade com cursos não reconhecidos até 22/11/2013 & 30 & 12,4 \\
\hline Total geral & $\mathbf{2 4 3}$ & $\mathbf{1 0 0}$ \\
\hline
\end{tabular}

Fonte: Ikuta (2016a, p. 159).

Relacionando os cursos selecionados que ofertaram bolsas do ProUni com os respectivos resultados das notas finais do CPC, é possível observar que quase metade, $53,5 \%$ ou 130 cursos, estão localizados na faixa do CPC 3 , considerado pelo INEP como resultado mínimo satisfatório. Em seguida, 14,8\% (36 cursos) estão localizados na faixa do CPC 4, 11,9\% (29 cursos) estão na faixa do CPC 2 e apenas 1,2\% ( 3 cursos) localizam-se na faixa do CPC 5, considerado como o que exibe maior correspondência com os critérios de qualidade exigidos.

Portanto, há pouquíssimos cursos nas faixas dos Conceitos 4 e 5; e quantidade considerável está na faixa 2 do CPC, considerada insatisfatória segundo os parâmetros do SINAES. Se considerarmos o critério de avaliação disposto na legislação do ProUni - "insuficiente" - como um sinônimo de insatisfatório, estes seriam cursos considerados insuficientes para os critérios de adesão ao ProUni, embora a legislação referente ao Programa atente que é preciso duas avaliações insuficientes consecutivas para que o curso seja descredenciado. Outro agravante entre esses cursos que ofertaram bolsas pelo ProUni é a quantidade considerável dos que estavam Sem Conceito (15 cursos, ou 6,2\%) e com status de ausência de reconhecimento até a data de aferição do CPC (30 cursos, ou 12,4\%), o que traz incertezas sobre a qualidade deles.

Na Tabela 3 estão os cursos com vagas ProUni selecionados, por tipo de bolsa ofertada durante o processo seletivo - se é integral (100\%) ou parcial (50\%), em relação aos resultados do CPC. Os 243 cursos ofertaram, juntos, 9.786 bolsas. Deste total, aproximadamente 62\% (6.099) são bolsas parciais e 38\% (3.687) são bolsas integrais.

Tabela 3 - Distribuição das bolsas ofertadas pelos cursos selecionados no processo seletivo do ProUni 1/2014, no município de São Paulo-SP, por tipo de bolsa, segundo resultados do Conceito Preliminar de Curso (CPC) 2012

\begin{tabular}{|l|c|c|c|c|}
\hline \multirow{2}{*}{ CPC - Resultado/situação } & \multicolumn{2}{c|}{ Bolsas Integrais } & \multicolumn{2}{c|}{ Bolsas Parciais } \\
\cline { 2 - 5 } & $\mathbf{n}^{\circ}$ & $\begin{array}{c}\text { \% do total de } \\
\text { bolsas }\end{array}$ & $\mathbf{n}^{\circ}$ & $\begin{array}{c}\text { \% do total de } \\
\text { bolsas }\end{array}$ \\
\hline CPC 2 & 391 & $4,0 \%$ & 461 & $4,7 \%$ \\
\hline CPC 3 & 1.982 & $20,3 \%$ & 4.170 & $42,6 \%$ \\
\hline CPC 4 & 941 & $9,6 \%$ & 846 & $8,6 \%$ \\
\hline CPC 5 & 9 & $0,1 \%$ & 7 & $0,1 \%$ \\
\hline Sem Conceito (SC) & 50 & $0,5 \%$ & 243 & $2,5 \%$ \\
\hline Unidade com cursos não reconhecidos até 22/11/2013 & 314 & $3,2 \%$ & 372 & $3,8 \%$ \\
\hline Total & 3.687 & $\mathbf{3 7 , 7 \%}$ & $\mathbf{6 . 0 9 9}$ & $\mathbf{6 2 , 3 \%}$ \\
\hline Total de Bolsas Integrais + Parciais & & & $\mathbf{9 . 7 8 6}$ \\
\hline
\end{tabular}

Fonte: Ikuta (2016a, p. 161). 
A maior parte $(42,6 \%$ do total, ou 4.170 bolsas) das bolsas são parciais e localizadas em cursos da faixa 3 do CPC. Outros 20,3\% (1.982) são bolsas integrais, também localizadas na faixa 3 ; ou seja, mais da metade $(62,9 \%)$ das bolsas do ProUni ofertadas no período analisado concentram-se em cursos que estão na faixa 3 do indicador de qualidade utilizado como referência, além de serem em sua maioria bolsas parciais. Nota-se, no entanto, que nas bolsas parciais há mais cursos com CPC 2 (4,7\% contra $4,0 \%$ nas bolsas integrais), cursos Sem Conceito $(2,5 \%$ contra $0,5 \%)$, e unidades com cursos não reconhecidos (3,8\% contra 3,2\%). Por outro lado, observa-se uma diminuição desse tipo de bolsa na faixa do CPC 4 (8,6\% contra 9,6\% nas bolsas integrais) e no CPC 5 observa-se uma relação semelhante e diminuta (0,1\% nos dois tipos de bolsas).

Dos 243 cursos com bolsas do ProUni selecionados, segundo grau acadêmico (Tabela 4), 141 são cursos de Bacharelado e 102 são Cursos Superiores de Tecnologia. Embora a maior parte dos cursos tenha se concentrado na faixa 3 do CPC, nota-se uma diferenciação importante na comparação realizada entre os dois graus acadêmicos. Proporcionalmente, os Tecnólogos acabam apresentando maior quantidade de cursos com Conceitos 3 (55,9\%), em relação aos de Bacharelado $(51,8 \%)$; no entanto, esses cursos também apresentam maior número de cursos com Conceitos $2(13,7 \%)$, considerados insatisfatórios em relação aos critérios de qualidade referenciados, do que, em proporção, os de Bacharelado $(10,6 \%)$. Ainda, os Cursos Superiores de Tecnologia apresentam número bastante reduzido de Conceitos 4 (4,9\%) em relação aos de Bacharelado, que apresentam $22 \%$ dos cursos nessa faixa. Na nota máxima, o Conceito 5, não há nenhum curso de Tecnologia, enquanto os de Bacharelado apresentam quantidade modesta $(2,1 \%)$. Na mesma comparação os CSTs possuem grande quantidade de cursos sem reconhecimento $(17,7 \%$ contra 8,5\% dos Bacharelados), além de número maior de cursos Sem Conceito (7,8\% dos CSTs, contra 5,0\% dos Bacharelados).

Tabela 4 - Distribuição dos cursos que ofereceram bolsas no processo seletivo do ProUni 1/2014, no município de São Paulo, SP, segundo resultados do Conceito Preliminar de Curso (CPC) 2012, por grau acadêmico

\begin{tabular}{|c|c|c|c|c|}
\hline \multirow{2}{*}{ CPC 2012 - Resultado/situação } & \multicolumn{2}{|c|}{ Bacharelados } & \multicolumn{2}{|c|}{$\begin{array}{l}\text { Cursos Superiores } \\
\text { de Tecnologia }\end{array}$} \\
\hline & $\mathbf{n}^{\circ}$ & $\%$ & $\mathbf{n}^{\circ}$ & $\%$ \\
\hline CPC 1 & 0 & - & 0 & - \\
\hline CPC 2 & 15 & 10,6 & 14 & 13,7 \\
\hline CPC 3 & 73 & 51,8 & 57 & 55,9 \\
\hline CPC 4 & 31 & 22 & 5 & 4,9 \\
\hline CPC 5 & 3 & 2,1 & 0 & 0 \\
\hline Sem Conceito (SC) & 7 & 5 & 8 & 7,8 \\
\hline Unidade com cursos não reconhecidos até $22 / 11 / 2013$ & 12 & 8,5 & 18 & 17,7 \\
\hline Total geral & 141 & 100 & 102 & 100 \\
\hline
\end{tabular}

Fonte: Ikuta (2016a, p. 163).

\section{Comparações entre cursos que ofertaram o ProUni e demais cursos (São Paulo-SP e Brasil)}

Durante a pesquisa também foi realizada uma comparação entre os 243 cursos sele- cionados do ProUni e os demais cursos que possuíam resultados no banco de dados do CPC em 2012, desagregando-os entre os ofertados no município de São Paulo-SP e os ofertados em todo o Brasil..$^{13}$ Dessa maneira, buscou-se

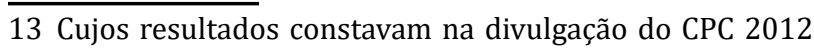


obter uma base de comparação da situação dos resultados de avaliação dos cursos participantes do ProUni selecionados, perante aos demais resultados de avaliação do país, evidenciando as semelhanças e as diferenças.

Os dados da Tabela 5 serão a base de informações para todas as demais comparações que se seguirão a partir de agora, durante o texto.

Tabela 5 - Distribuição dos cursos que ofereceram bolsas no processo seletivo do ProUni 1/2014 no município de São Paulo, SP, em relação aos demais cursos do município e do Brasil, segundo resultados do Conceito Preliminar de Curso (CPC) 2012.

\begin{tabular}{|c|c|c|c|c|c|c|}
\hline \multirow[t]{2}{*}{ CPC 2012 - Resultado/situação } & \multicolumn{2}{|c|}{$\begin{array}{c}\text { Cursos com } \\
\text { bolsas do ProUni } \\
\text { São Paulo - SP }\end{array}$} & \multicolumn{2}{|c|}{$\begin{array}{c}\text { Cursos } \\
\text { São Paulo - } \\
\text { SP }^{1}\end{array}$} & \multicolumn{2}{|c|}{$\begin{array}{l}\text { Cursos - } \\
\text { Brasil }^{2}\end{array}$} \\
\hline & $n^{\circ}$ & $\%$ & $n^{\circ}$ & $\%$ & $n^{\circ}$ & $\%$ \\
\hline CPC 1 & 0 & - & 0 & - & 16 & 0,2 \\
\hline CPC 2 & 29 & 11,9 & 37 & 18,1 & 715 & 10,5 \\
\hline СРC 3 & 130 & 53,5 & 83 & 40,7 & 2.944 & 43,1 \\
\hline CPC 3 (sob judice) & 0 & - & 0 & - & 1 & 0,0 \\
\hline СРС 4 & 36 & 14,8 & 23 & 11,3 & 1.382 & 20,2 \\
\hline CPC 5 & 3 & 1,2 & 1 & 0,5 & 96 & 1,4 \\
\hline Ato Vencido & 0 & - & 2 & 1,0 & 4 & 0,1 \\
\hline Sem Conceito (SC) & 15 & 6,2 & 35 & 17,2 & 586 & 8,6 \\
\hline Sob supervisão & 0 & - & 0 & - & 12 & 0,2 \\
\hline $\begin{array}{l}\text { Unidade com cursos não reconhecidos até } \\
22 / 11 / 2013\end{array}$ & 30 & 12,4 & 23 & 11,3 & 1.062 & 15,5 \\
\hline Descredenciada & 0 & - & 0 & - & 16 & 0,2 \\
\hline Total geral & 243 & 100 & 204 & 100 & 6.834 & 100 \\
\hline
\end{tabular}

Fonte: Ikuta (2016a, p. 167).

(1) Total de Unidades de Observação em São Paulo-SP avaliadas pelo CPC 2012, excluindo as Unidades de Observação identificadas como ProUni, analisadas na primeira coluna.

(2) Total de Unidades de Observação no Brasil avaliadas pelo CPC 2012, excluindo as Unidades de Observação identificadas como ProUni, analisadas na primeira coluna.

Os 243 cursos que ofertaram vagas do ProUni representaram 3,7\% de todos os cursos avaliados no Brasil pelo CPC no ano referido (7.077 cursos); em relação ao município de São Paulo-SP, a abrangência dos cursos com ProUni selecionados representou mais da metade dos cursos (57\%).

Observa-se na Tabela 5 que, em proporção, os cursos identificados com ProUni alcançaram resultados melhores (em termos de atendimento aos critérios estabelecidos de qualidade do CPC) nas faixas 2, 4 e 5 do que o observado no quadro dos resultados obtidos entre o

(INSTITUTO NACIONAL DE PESQUISAS EDUCACIONAIS ANÍSIO TEIXEIRA, 2014b), que totalizaram 7.077 cursos (unidades de observação). grupo dos demais cursos do município de São Paulo-SP (204 cursos). Além disso, na faixa SC (Sem Conceito) identifica-se, na análise, uma proporção muito menor de cursos do ProUni $(6,2 \%)$ do que os demais cursos de São Paulo $(17,2 \%)$.

Da mesma forma que com os cursos de São Paulo-SP, foi realizada comparação com os demais cursos do Brasil avaliados pelo CPC em 2012 (terceira coluna). Neste caso foram considerados os 6.834 cursos, já excluído o grupo de 243 cursos identificados como participantes do ProUni. Foram observados melhores resultados, em relação ao $\mathrm{CPC}$, no grupo dos cursos do Brasil do que nos cursos com vagas do ProUni, e até mesmo do que 
nos demais cursos de São Paulo-SP, já que, na comparação, em proporcionalidade, foi verificado que no Brasil há menos cursos CPC $2 \mathrm{e}$ mais cursos CPC 4 e CPC 5 do que nos outros grupos. Além disso, há também uma proporção menor de cursos CPC 3 (43,1\% contra $53,5 \%$ do ProUni); entretanto, essa proporção é ligeiramente maior quando se compara com os cursos de São Paulo-SP (43,1\% contra $40,7 \%$ ). Contudo, um aspecto positivo é que, nas faixas Sem Conceito e de unidades sem reconhecimento, os cursos com oferta do ProUni foram menos frequentes do que o restante dos cursos do Brasil $(6,2 \%$ contra $8,6 \%$ e $12,4 \%$ contra $15,5 \%$, respectivamente).

A variável Organização Acadêmica da IES (Tabela 6) está inclusa na divulgação dos resultados do CPC apenas com o intuito de caracterização dos cursos. Contudo, sua análise mostrou-se interessante, já que é possível perceber que os cursos que ofertam bolsas do ProUni são oferecidos em Universidades (47\%), Faculdades (27\%) e Centros Universitários (26\%).

Tabela 6 - Distribuição dos cursos que ofereceram bolsas no processo seletivo do ProUni 1/2014, no município de São Paulo, SP, em relação aos demais cursos do município e do Brasil, por Organização Acadêmica da Instituição ofertante, segundo resultados do Conceito Preliminar de Curso 2012

\begin{tabular}{|c|c|c|c|c|c|c|}
\hline \multirow[t]{2}{*}{ Organização Acadêmica } & \multicolumn{2}{|c|}{$\begin{array}{c}\text { Cursos com bolsas } \\
\text { do ProUni } \\
\text { São Paulo - SP } \\
\end{array}$} & \multicolumn{2}{|c|}{$\begin{array}{c}\text { Cursos } \\
\text { São Paulo - SP }\end{array}$} & \multicolumn{2}{|c|}{$\begin{array}{l}\text { Cursos } \\
\text { Brasil }\end{array}$} \\
\hline & $\mathbf{n}^{\circ}$ & $\%$ & $\mathbf{n}^{\circ}$ & $\%$ & $\mathbf{n}^{\circ}$ & $\%$ \\
\hline Universidade & 113 & 46,5 & 50 & 24,5 & 2.150 & 31,5 \\
\hline Centro Universitário & 64 & 26,3 & 48 & 23,5 & 888 & 13,0 \\
\hline Faculdade & 66 & 27,2 & 105 & 51,5 & 3.753 & 54,9 \\
\hline Instituto Federal de Educação, Ciência e Tecnologia & - & - & 1 & 0,5 & 41 & 0,6 \\
\hline Centro Federal de Educação Tecnológica & - & - & - & - & 2 & 0,0 \\
\hline Total & 243 & 100 & 204 & 100 & 6.834 & 100 \\
\hline
\end{tabular}

Fonte: Ikuta (2016a, p. 175).

Os dados corroboram o quadro visto anteriormente, em que a oferta do Programa é marcada pela concentração em IES de grande porte, de grandes grupos educacionais. Essa situação acaba reforçando o quadro de pouca diversidade institucional e relaciona-se ao processo de oligopolização que o setor de educação superior vem passando desde o início dos anos 2000, apresentando tendências de concentração institucional, fusões, aquisições e financeirização das empresas educacionais (CARVALHO, 2013).

A questão da concentração em Universidades torna-se ainda mais evidente quando observada a comparação dos 243 cursos que ofertam vagas do ProUni com os demais cursos ofertados no município de São Paulo-SP e no Brasil. Nota-se que, nos cursos de São Paulo-SP e do Brasil há um predomínio muito maior da oferta em Faculdades (51\% e 55\%, respectivamente) do que no ProUni, que apresenta somente $27 \%$.

A segunda parte da análise, considerando a mesma seleção de cursos, centrou-se nos resultados obtidos nas notas finais do CPC 2012 (INSTITUTO NACIONAL DE PESQUISAS EDUCACIONAIS ANÍSIO TEIXEIRA, 2014b) segundo as áreas de enquadramento.

Foram escolhidas as cinco áreas que registraram maior número de cursos com ProUni (dentre os 243 cursos analisados), que são: Administração (36 cursos), Ciências Contábeis (28 cursos), Tecnologia em Gestão de Recursos Humanos (25 cursos), Tecnologia em Logística ( 21 cursos) e Direito (20 cursos). 
Gráfico 2 - Distribuição dos cursos de Administração que ofereceram bolsas no processo seletivo do ProUni 1/2014, no município de São Paulo, SP, em relação aos demais cursos do município e do Brasil, segundo resultados do Conceito Preliminar de Curso (CPC) 2012

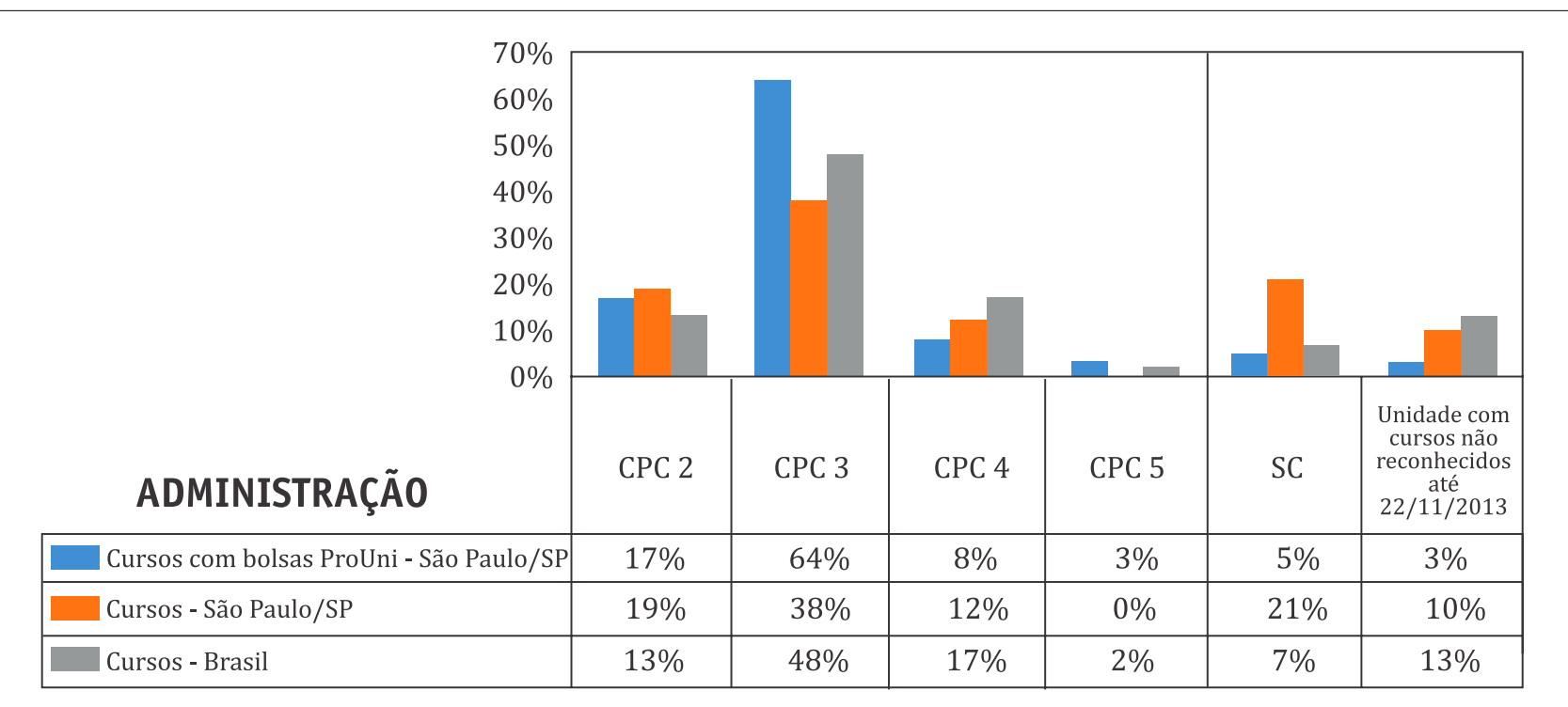

Fonte: Ikuta (2016a, p. 170).

Em relação aos cursos de Administração (Gráfico 2), verificou-se uma concentração muito maior, em proporção, de cursos selecionados com ProUni com CPC 3 (64\%) do que os demais cursos do município (38\%) e do Brasil (48\%). Entretanto, por conta da distribuição padronizada, torna-se importante olhar para as demais faixas do CPC: há menos cursos ofertantes do ProUni na faixa do CPC 4 do que nos demais grupos. Por outro lado, há menos cursos ofertantes de ProUni classificados como Sem Conceito (5\% contra $21 \%$ do município e $7 \%$ do Brasil), assim como dos não reconhecidos naquele momento (3\% contra $10 \%$ no município e $13 \%$ no Brasil).

Em relação aos cursos de Ciências Contábeis, no Gráfico 3, identificaram-se muitos cursos na faixa CPC 2 (18\%), considerada insatisfatória,

Gráfico 3 - Distribuição dos cursos de Ciências Contábeis que ofereceram bolsas no processo seletivo do ProUni 1/2014, no município de São Paulo-SP, em relação aos demais cursos do município e do Brasil, segundo resultados do Conceito Preliminar de Curso (CPC) 2012

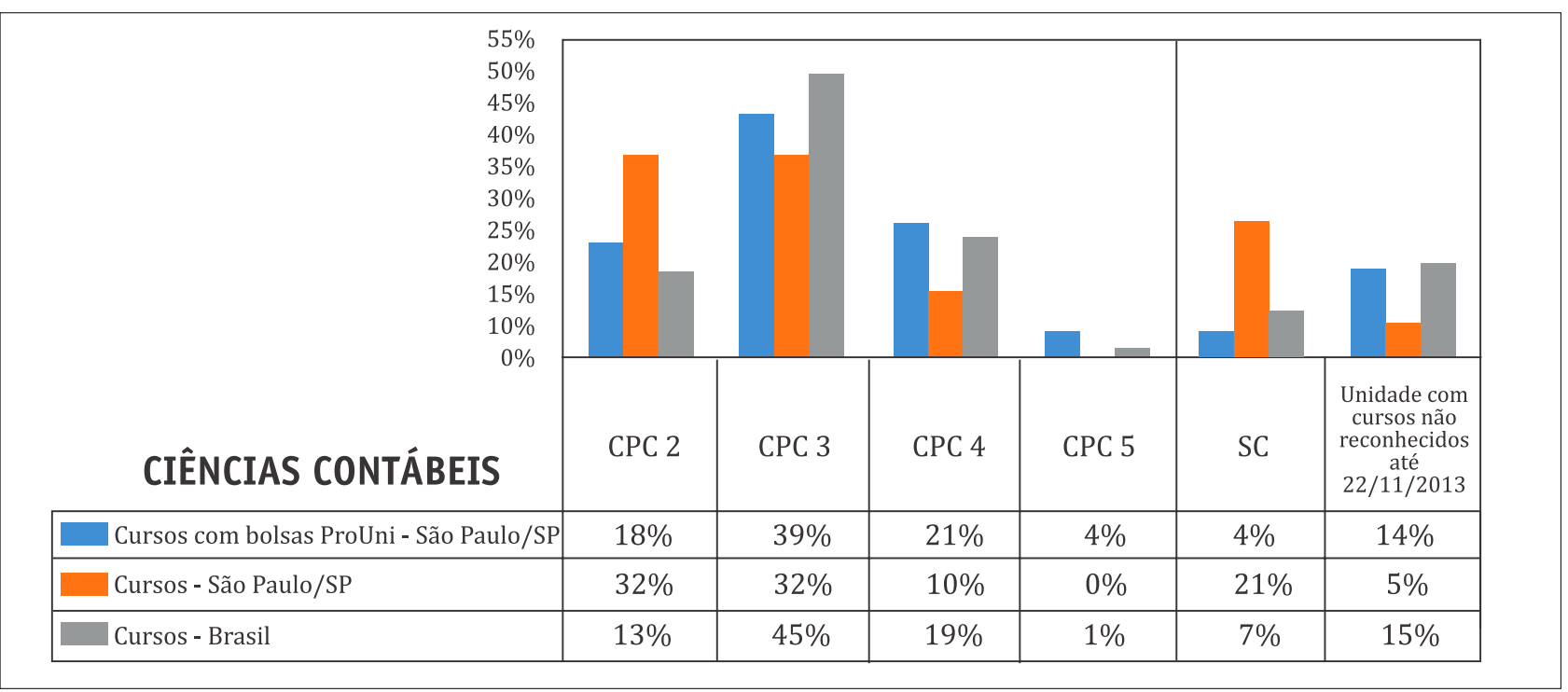

Fonte: Ikuta (2016a, p. 171). 
embora em menor proporção do que os demais cursos de São Paulo-SP (32\%). Nas faixas mais altas do CPC, os resultados mostraram significativa vantagem dos cursos ofertantes do ProUni (21\% na faixa 4 , e $4 \%$ na faixa 5) em relação aos demais cursos analisados (no município são $10 \%$ e $0 \%$, respectivamente; e no Brasil, 19\% e 1\%). Ainda, havia muitos cursos em São Paulo-SP que estavam Sem Conceito (21\%), ao passo que da seleção dos que ofertavam o ProUni havia apenas 4\%.

Focalizando a análise em torno de um Curso Superior de Tecnologia (Gestão de Recursos Humanos), no Gráfico 4, primeiramente é possível observar que os resultados são visivelmente inferiores em relação aos dois cursos de Bacharelado analisados anteriormente (Administração e Ciências Contábeis), principalmente pela ausência de cursos com CPC 5 e aumento dos cursos não reconhecidos em todos os grupos analisados (24\% com ProUni, $8 \%$ no município e $21 \%$ no Brasil). Também foi verificado que os cursos que ofertaram ProUni possuem resultados piores na faixa CPC 4, ou seja, apresentam apenas 4\% entre os cursos analisados, enquanto os índices no município e no Brasil são maiores - 15\% e $17 \%$, respectivamente.

Gráfico 4 - Distribuição dos cursos de Tecnologia em Gestão de Recursos Humanos que ofereceram bolsas no processo seletivo do ProUni 1/2014, no município de São Paulo-SP, em relação aos demais cursos do município e do Brasil, segundo resultados do Conceito Preliminar de Curso (CPC) 2012

\begin{tabular}{|c|c|c|c|c|c|c|c|}
\hline \multicolumn{8}{|c|}{$60 \%$} \\
\hline \multicolumn{8}{|c|}{$50 \%$} \\
\hline \multicolumn{8}{|c|}{$40 \%$} \\
\hline \multicolumn{8}{|c|}{$30 \%$} \\
\hline \multicolumn{8}{|c|}{$20 \%$} \\
\hline \multicolumn{8}{|c|}{$10 \%$} \\
\hline $\begin{array}{l}\text { TECNOLOGIA EM GESTÃO } \\
\text { DE RECURSOS HUMANOS }\end{array}$ & $0 \%$ & CPC 2 & CPC 3 & CPC 4 & CPC 5 & 1 & $\begin{array}{l}\text { Unidade com } \\
\text { cursos nã̃ } \\
\text { reconhecidos } \\
\text { até } \\
22 / 11 / 2013\end{array}$ \\
\hline Cursos com bolsas ProUni - São Paul & o/SP & $16 \%$ & $52 \%$ & $4 \%$ & $0 \%$ & $4 \%$ & $24 \%$ \\
\hline Cursos - São Paulo/SP & & $23 \%$ & $54 \%$ & $15 \%$ & $0 \%$ & $0 \%$ & $8 \%$ \\
\hline Cursos - Brasil & & $13 \%$ & $45 \%$ & $17 \%$ & $1 \%$ & $3 \%$ & $21 \%$ \\
\hline
\end{tabular}

Fonte: Ikuta (2016a, p. 171).

A área de Tecnologia em Logística (Gráfico 5) apresenta alta concentração de cursos que estavam sem reconhecimento naquele momento, com exceção dos cursos que ofertavam o ProUni (9\% dos cursos com ProUni, 36\% no município e $24 \%$ no Brasil) - ainda que, observando somente os cursos com ProUni, é possível perceber que há uma concentração muito maior na faixa 3 do CPC, com aproximadamente $62 \%$ dos cursos analisados, em relação aos demais grupos (37\% em São Paulo-SP e 38\% no Brasil).

A última das cinco áreas de enquadramento analisadas é a dos cursos de Direito (Gráfico
6). Foi observado um resultado altamente concentrado na faixa 3 do CPC em todos os grupos de cursos analisados $(65 \%$ dos cursos com vagas do ProUni, 92\% do município e $50 \%$ no Brasil), como é de se esperar, porém, de forma muito intensa no município. Ocorreu significativa vantagem dos cursos de Direito ofertantes de ProUni na faixa 4 do CPC (20\%) em relação aos cursos do município (8\%), e patamar semelhante em relação ao Brasil (21\%). Já na faixa 5, praticamente não há cursos, com exceção de $1 \%$ verificado nos demais cursos do total do país. 
Gráfico 5 - Distribuição dos cursos de Tecnologia em Logística que ofereceram bolsas no processo seletivo do ProUni 1/2014, no município de São Paulo-SP, em relação aos demais cursos do município e do Brasil, segundo resultados do Conceito Preliminar de Curso (CPC) 2012

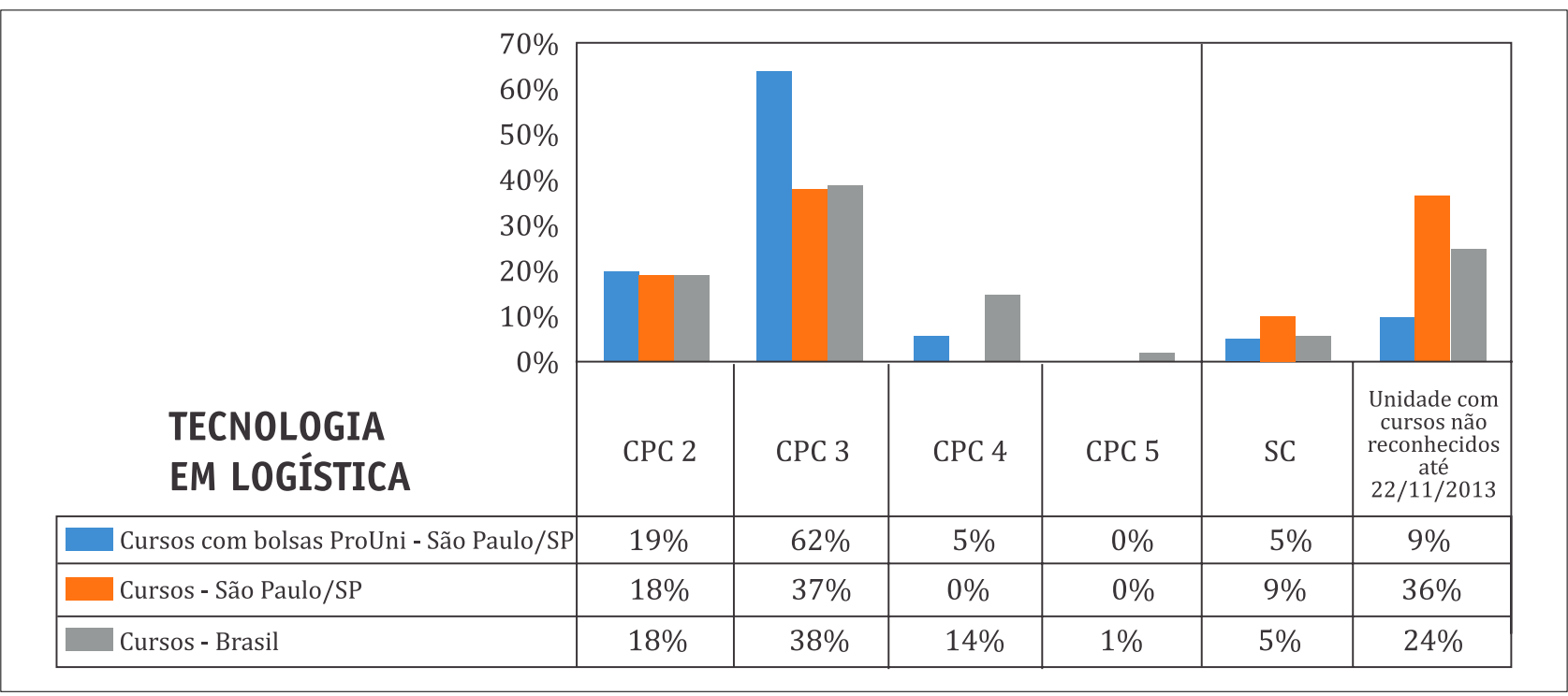

Fonte: Ikuta (2016a, p. 172).

Gráfico 6 - Distribuição dos cursos de Direito que ofereceram bolsas no processo seletivo do ProUni 1/2014, no município de São Paulo-SP, em relação aos demais cursos do município e do Brasil, segundo resultados do Conceito Preliminar de Curso (CPC) 2012

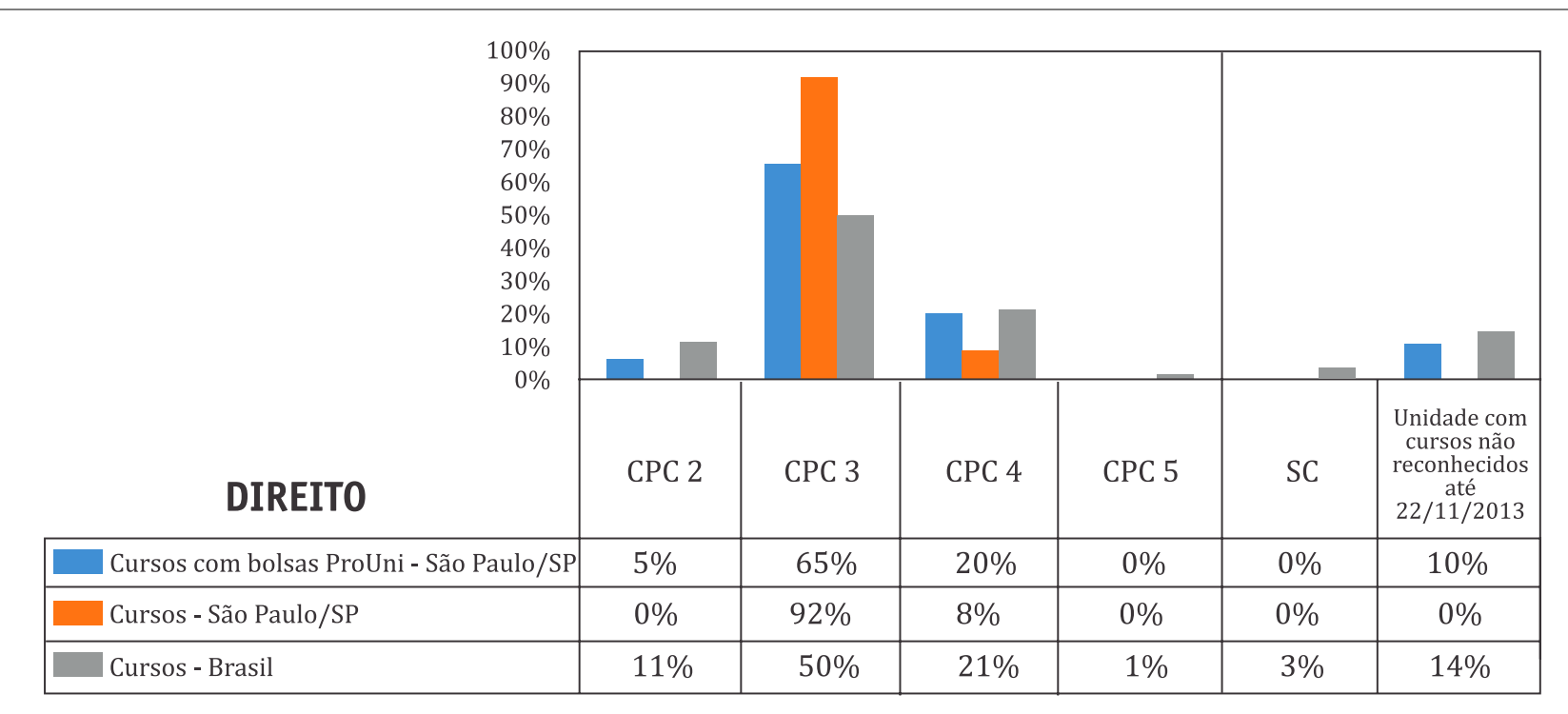

Fonte: Ikuta (2016a, p. 173).

\section{Considerações Finais}

0 texto apresentou resultados de pesquisa que investigou a questão da qualidade dos cursos que ofertaram bolsas pelo ProUni, com base nos resultados de avaliação de cursos do Conceito Preliminar de Curso (CPC), considerado o indicador oficial de qualidade no país.
É importante ponderar que o grupo de cursos selecionado para a análise possui limitações metodológicas, sendo este um trabalho de análise descritiva e exploratória. Sabe-se que a nota final do CPC não reflete, sozinha, os diversos componentes que são avaliados e 
que constituem os critérios de qualidade exigidos no processo. Portanto, não se pretende realizar a generalização dos resultados para o universo de cursos com oferta pelo ProUni. Ainda assim, o indicador do CPC é o que permite, atualmente, uma comparação abrangente da avaliação da qualidade desses cursos em relação a todos os demais existentes na educação superior brasileira.

Em síntese, no caso dos 243 cursos que ofertaram vagas do ProUni selecionados para análise, nem sempre apresentam-se resultados ligados à baixa qualidade (ou considerados insatisfatórios). Este ponto é importante pois, conforme explicitado na seção dedicada ao ProUni, é uma problemática bastante debatida na literatura sobre o tema, pois ainda existem muitos entraves para se mensurar a qualidade dos cursos participantes, bem como das instituições que os ofertam, considerando que estão na esfera particular de ensino.

A partir dessa lacuna de investigação, pôdese aferir da pesquisa realizada que os cursos selecionados que ofertaram o ProUni acompanharam a tendência de resultados de avaliação registrados nos demais cursos do município e do país, ou seja, não destoam do quadro geral da educação superior brasileira - que, vale lembrar, inclui os cursos das instituições públicas. E ainda, em alguns casos, foram registrados resultados superiores dos cursos com vagas do ProUni em relação ao critério de qualidade estabelecido - como na comparação com os demais cursos do município de São Paulo-SP, em que os cursos com ProUni alcançaram resultados melhores nas faixas mais altas do CPC.

Da análise comparativa entre os cursos que ofertaram o ProUni, os demais cursos de São Paulo-SP e do Brasil, segmentados por área de enquadramento (Administração, Ciências Contábeis, Direito, Logística e Gestão de Recursos Humanos), foi possível destacar o aspecto preocupante em que há ausência, ou presença extremamente diminuta, de cursos com CPC 5 em todos os grupos de cursos, sendo esse o CPC considerado como o que possui maior correspondência com os critérios de qualidade exigidos. Os cursos com vagas do ProUni, no entanto, alcançaram melhores resultados em cursos de bacharelado (Ciências Contábeis e Direito) na faixa 4 do $\mathrm{CPC}$, em relação aos demais cursos.

Entre o próprio grupo de cursos que ofertaram vagas do ProUni, a correspondência com os critérios de qualidade mostrou-se diversa quando considerados o grau acadêmico e o tipo de bolsa ofertada. As bolsas parciais concentraram-se em cursos que obtiveram resultado visivelmente pior em relação ao indicador do CPC, em relação à distribuição observada no caso das bolsas integrais. Percebeu-se, também, que os Cursos Superiores de Tecnologia apresentaram pior resultado nos indicadores em relação aos cursos de Bacharelado. Seria necessário observar se, historicamente, os CSTs possuem grande oferta nos processos seletivos do ProUni; entretanto, não foi possível conseguir uma série histórica dessas informações.

Houve maior incidência de oferta dos cursos com bolsas do ProUni em IES de grande porte, predominantemente Universidades - possívelmente também pelo fato do grupo com ProUni analisado estar restrito ao local de oferta do município de São Paulo-SP. Sabe-se que o setor de educação superior é extremamente pulverizado em termos de IES, concentrando um grande número de instituições de pequeno porte; porém, no caso de políticas com o caráter de renúncia fiscal, como é o caso do ProUni, a oferta costuma se concentrar, evidentemente, em IES com maior oferta de vagas e de matriculados.

Por fim, emergiu o questionamento: a avaliação dos cursos participantes do ProUni consegue realizar-se efetivamente e assegurar um padrão mínimo de qualidade aos cursos?

A legislação referente ao Programa assinala que é preciso ocorrer duas avaliações consecutivas com resultado insuficiente, segundo critérios do SINAES (ainda que sem especificar diretamente qual o indicador utilizado), para que um curso seja desvinculado do Programa. 
Considerando que muitos cursos obtiveram CPC insatisfatório em 2012, ou sequer foram avaliados, e na prática ofertaram bolsas ProUni no determinado processo seletivo, questiona-se a formação acadêmica dos beneficiários do ProUni - que pode estar comprometida em relação à qualidade ofertada, considerando os parâmetros oficiais de avaliação de cursos.

Soma-se a essa situação o fato de que embora o CPC seja divulgado anualmente, as avaliações de cada área, que são atreladas ao ENADE, possuem periodicidade trienal no SINAES - fato que, de certa forma, limita a quantidade de cursos a serem avaliados por ano. Tal processo revela um descompasso entre os cursos oferecidos e o período de avaliação deles, já que, na prática, um curso que obteve resultados de avaliação insatisfatórios pode ter oferecido bolsas do ProUni por seis anos, ou até mais, considerando as regras de avaliação trienal e da legislação do Programa. Portanto, esse processo pode dificultar, ainda mais, o controle da qualidade dos cursos que ofertam bolsas pelo ProUni, bem como o desvinculamento caso não haja atendimento aos critérios de qualidade.

Nesse sentido, parece importante questionar se a atual forma de vinculação entre a avaliação de cursos de graduação, que é realizada pelo SINAES, e os propósitos de avaliação que vigoram no ProUni são realmente suficientes, ou poderiam ser aperfeiçoados, a fim de estabelecer maior rigor para os cursos que futuramente oferecerão bolsas pelo Programa.

\section{REFERÊNCIAS}

ALMEIDA, Wilson Mesquita de. Ampliação do acesso ao ensino superior privado lucrativo brasileiro: um estudo sociológico com bolsistas do Prouni na cidade de São Paulo. 2012. 294 f. Tese (Doutorado em Sociologia) - Programa de Pós-Graduação em Sociologia, Universidade de São Paulo (USP), São Paulo, 2012.

BARREYRO, Gladys Beatriz. De exames, rankings e mídia. Avaliação, Campinas/Sorocaba, SP, v. 13, n. 3, p. 863-868, nov. 2008.

BARREYRO, Gladys Beatriz; COSTA, Fábio Luciano
Oliveira. Las políticas de educación superior em Brasil en la primera década del siglo XXI: algunas evidencias sobre impactos positivos em la equidad. Revista Mexicana de Investigación Educativa, v. 20, n. 64, p. 17-46, jan./mar. 2015.

BARREYRO, Gladys Beatriz; ROTHEN, José Carlos. Percurso da avaliação da educação superior nos Governos Lula. Educação e Pesquisa, São Paulo, v. 40, n. 1, p. 61-76, jan./mar. 2014.

BITTENCOURT, Hélio Radke. Et al. Uma análise da relação entre os conceitos Enade e IDD. Estudos em Avaliação Educacional, v. 19, n. 40, p. 247-262, maio/ago. 2008.

BRASIL. Constituição da República Federativa do Brasil. 1988. São Paulo: Imprensa Oficial, 1999.

BRASIL. Lei $\mathrm{n}^{\circ}$ 10.861, de 14 de abril de 2004. Institui o Sistema Nacional de Avaliação da Educação Superior - SINAES e dá outras providências. Diário Oficial [da] República Federativa do Brasil: seção 1, Brasília, DF, n. 72, p. 3-4, 15 abr. 2004.

BRASIL. Lei no 11.096, de 13 de janeiro de 2005. Institui o Programa Universidade para Todos PROUNI, regula a atuação de entidades beneficentes de assistência social no ensino superior; altera a Lei no 10.891, de 9 de julho de 2004, e dá outras providências. Diário Oficial da União: seção 1 , Brasília, DF, n. 10, p. 7-8, 14 jan. 2005.

BRASIL. Ministério da Educação. Portaria Normativa no 40, de 29 de dezembro de 2010. Institui o e-MEC, sistema eletrônico de fluxo de trabalho e gerenciamento de informações relativas aos processos de regulação, avaliação e supervisão da educação superior no sistema federal de educação, e o Cadastro e-MEC de Instituições e Cursos Superiores e consolida disposições sobre indicadores de qualidade, banco de avaliadores (Basis) e o Exame Nacional de Desempenho de Estudantes (ENADE) e outras disposições. Diário Oficial da União: seção 1, Brasília, DF, n. 249, p. 23-31, 29 dez. 2010.

BRASIL. Lei no 12.527, de 18 de novembro de 2011. Regula o acesso a informações previsto no inciso XXXIII do art. 5o, no inciso II do $\S 3^{\circ}$ do art. 37 e no $\S 2^{\circ}$ o do art. 216 da Constituição Federal; altera a Lei no 8.112, de 11 de dezembro de 1990; revoga a Lei no 11.111, de 5 de maio de 2005, e dispositivos da Lei no 8.159, de 8 de janeiro de 1991; e dá outras providências. Diário Oficial da União: seção 1, Brasília, DF, n. 221-A, edição extra, p. 1-4, 18 nov. 2011. BRASIL. Ministério da Educação. Programa 
Universidade para Todos. Dados e Estatísticas. 2017. Brasília, DF, 2017. Disponível em: http:// prouniportal.mec.gov.br. Acesso em: 28 dez. 2017.

CARVALHO, Cristina Helena Almeida de. O PROUNI no Governo Lula e o jogo político em torno do acesso ao ensino superior. Educação \& Sociedade, Campinas, SP, v. 27, n. 96, p. 979-1000, out. 2006.

CARVAlHo, Cristina Helena Almeida de. A mercantilização da educação superior brasileira e as estratégias de mercado das instituições lucrativas. Revista Brasileira de Educação, Rio de Janeiro, v. 18, n. 54, p. 761-801, jul./set. 2013.

CATANI, Afrânio Mendes; HEY, Ana Paula; GILIOLI, Renato de Sousa Porto. PROUNI:

democratização do acesso às Instituições de Ensino Superior? Educar, Curitiba, n. 28, p.

125-140, 2006.

IKUTA, Camila Yuri Santana. A qualidade no Programa Universidade para Todos (ProUni) segundo os resultados de avaliação de cursos do Sistema Nacional de Avaliação da Educação Superior (SINAES). 2016a. 226 f. Dissertação (Mestrado em Educação) - Programa de PósGraduação em Educação, Universidade de São Paulo (USP), São Paulo, 2016a.

IKUTA, Camila Yuri Santana. Sobre o conceito preliminar de curso: concepção, aplicação e mudanças metodológicas. Estudos em Avaliação Educacional, São Paulo, v. 27, n. 66, p. 938-969, set./dez. 2016b.

INSTITUTO NACIONAL DE PESQUISAS EDUCACIONAIS ANÍSIO TEIXEIRA (INEP). Censo da Educação Superior 2004 - Resumo Técnico. Brasília, DF 2005.

INSTITUTO NACIONAL DE PESQUISAS EDUCACIONAIS ANÍSIO TEIXEIRA (INEP). Nota Metodológica - Indicadores de Qualidade da Educação Superior 2012. Brasília, DF, 2013. Disponível em: http://download.inep.gov.br/ educacao_superior/ enade/notas_tecnicas/2012/ nota_metodologica_indicadores_2012.pdf. Acesso em: 04 mai. 2018.

INSTITUTO NACIONAL DE PESQUISAS EDUCACIONAIS ANÍSIO TEIXEIRA (INEP). Nota Técnica no 70 - Utilização dos Insumos do Questionário do Estudante Aplicado em 2013.
Brasília, DF, 2014a. Disponível em: http:// download. inep.gov.br/educacao_superior/enade/ notas_tecnicas/2013/nota_tecnica_n_70_2014 utilizacao_insumos_questionario_estudante_2013. pdf. Acesso em: 04 mai. 2017.

INSTITUTO NACIONAL DE PESQUISAS EDUCACIONAIS ANÍSIO TEIXEIRA (INEP). Resultados do Conceito Preliminar de Curso 2012. Brasília, DF, 2014b. Disponível em: http:// download.inep.gov.br/educacao_superior/enade/ planilhas/2012/cpc_2012_site_2014_03_14.xls. Acesso em: 12 maio 2015.

INSTITUTO NACIONAL DE PESQUISAS EDUCACIONAIS ANÍSIO TEIXEIRA (INEP). Sinopses Estatísticas da Educação Superior - Graduação - 2013. Brasília, DF, 2015. Disponível em: http://portal.inep.gov.br/superior-censosuperiorsinopse. Acesso em: 03 fev. 2016.

MOROSINI, Marilia Costa. Qualidade na educação superior: tendências do século. Estudos em Avaliação Educacional, São Paulo, v. 20, n. 43, p. 165-186, maio/ago. 2009.

NUNES, Edson de Oliveira; FERNANDES, Ivanildo; ALBRECHT, Julia. Regulação e Ensino Superior no Brasil. Documento de Trabalho ${ }^{\circ} 112$, Observatório Universitário, Rio de Janeiro. 2014. Disponível em: http://www.observatoriouniversitario.org. br/documentos_de_trabalho/documentos_de_ trabalho_112.pdf. Acesso em: 16 jan. 2018.

PAULA, Maria de Fátima de. As propostas de democratização do acesso ao Ensino Superior

do Governo Lula: reflexões para o debate. Avaliação, Campinas, SP, v. 11, n. 1, p. 133-147, mar. 2006.

RISTOFF, Dilvo. 0 novo perfil do campus brasileiro: uma análise do perfil socioeconômico do estudante de graduação. Avaliação, Campinas, SP, v. 19, n. 3, p. 723-747, nov. 2014.

SOUSA, José Vieira de. Aumento de vagas ociosas na educação superior brasileira (2003-2008): redução do poder indutor da expansão via setor privado? In: REUNIÃO ANUAL DA ANPEd, 33., 2010, Caxambu. Anais eletrônicos [...]. Caxambu, MG: ANPEd, 2010. Disponível em: http://www.anped11.uerj.br/ AUMENTO DEVAGAS.pdf. Acesso em: 15 ago. 2017.

Recebido em: 15/12/2019 Aprovado em: 22/07/2020

(cc) B EY-NC Este é um artigo publicado em acesso aberto sob uma licença Creative Commons. 